has provided the necessary context and background on basic life-history/natural history so readers, even if unfamiliar with Pacific salmon, will be able to follow. In fact, throughout the book he contrasts and compares interesting characteristics among species (and among populations) to reveal their incredible diversity. Quinn has also provided enough background on techniques in fisheries science that readers can gain an appreciation for the challenges in answering some questions. For example, in the migration chapter he discusses techniques for monitoring individual behaviour (e.g., conventional tagging, acoustic telemetry). For most trained fisheries scientists, some of the background material will be superfluous. However, it is necessary considering the broad audience. In the end, I believe that even the most experienced fisheries scientists will find the writing style and content to be refreshing and not too simplistic.

The book includes coverage of some rather novel topics within the 19 chapters. For example, this is the first fish ecology book that I have encountered that includes a chapter on the ecology of dead fish. Several years ago such a chapter would have been rather short. However, the explosion of research in the past few years on the role of salmon carcasses in the environment, much of which has been conducted by Quinn and his associates, enables such a chapter to be developed. This chapter in particular will be of interest to more general ecologists and naturalists. The chapters associated with adult migration and reproduction (2 through 6 ) are also exceptionally strong coincident with the authors expertise in those areas. That said, there were no chapters that I would consider weak, with my preference for some perhaps reflecting my personal interests and biases.

The text is well referenced but not to the extent that one feels like they are wading through a scientific manuscript. Quinn provides ample detail on the studies he summarizes, but more importantly, he provides extensive commentary and interpretation. He also poses questions that will serve as a springboard for countless graduate student projects. This is what really separates this book from other works that are available. His syntheses draw together data from disparate studies, often using this information to develop original figures or

\section{Venomous Reptiles of the Western Hemisphere}

By Jonathan A. Campbell and William W. Lamar. 2 volumes. 2004. Comstock Publishing Associates, Cornell University Press, Ithaca, New York. 870 pages.

This is a second edition, revised and expanded, of the authors' The Venomous Reptiles of Latin America published in 1989. Added to the southern species covered in that book are those occurring in North America. The authors are from the University of Texas at Arlington and at Tyler, respectively. Additional contributors are Edmund D. Brodie III and Jr. Indiana University and Utah State University, Ronald L. Gutbertlet Jr. and conceptual diagrams. His goal was to "inform and excite" the reader - a goal that I would argue he has more than achieved. The chapters are not exhaustive in coverage. Instead, Quinn has focused on selecting examples that contribute to an overall understanding of Pacific salmon and are interesting. Although his intent was not to advocate (as he reveals in the preface), the last chapter did provide some interesting final thoughts. As "the" authority on Pacific salmon, I would have appreciated if Quinn had expanded these sections on the current status and prognosis of Pacific salmon. It was this section that I found particularly fascinating, but it left me desiring more.

The book is available in both hard and paperback form and is reasonably priced. The photograph on the cover is stunning (taken by the author). Other photographs and plates within the text are equally interesting and of high quality. Exceptional care has been taken in developing crisp and clear figures that have consistent formatting throughout (e.g., axis, font, symbols). The author has eliminated details of most statistical tests presented by other authors and urges readers to consult original sources. Brief summaries are provided at the end of each chapter and the book concludes with an extensive index. Collectively, these characteristics further elevate the value of this work and contribute to its flow and ease of reading.

There are few groups of fishes, or other animals for that matter, where one could develop a book such as this that would have appeal to anyone with an interest in animal ecology. The book is extremely engaging and will leave the reader with a desire to don a pair of waders and explore some of these topics first hand. I am confident that Quinn's book will become a well-read and well-cited contribution. Shortly this book will be found on the office shelves of most salmon biologists, but I suspect it will be equally common in the personal libraries of armchair naturalists, anglers, and others with broad interests in ecology.

Steven J. Cooke

Centre for Applied Conservation Research, Department of Forest Sciences, University of British Columbia, 2424 Main Mall, Vancouver, British Columbia V6T 1Z4 Canada

Michael B. Harvey University of Texas at Tyler and East Tennesse State University, Robert Norris Stanford University Medical Center, David A. Warrell, Centre for Tropical Medicine, University of Oxford, and Vinicius Xavier da Silva Universidade de Sao Paulo.

Theirs is an accomplishment of monumental proportions in size and collation of information. It is of coffee table format and includes a staggering 1500 colour photographs, 135 of them pictures of snakebite effects about which the authors' relate that a the first edition reviewer termed them their "hideous picture album". 
The species accounts begin with two lizards (the Gila Monster and the Mexican Beaded Lizard, genus Heloderma), the sole members of their family and the only venomous reptiles other than snakes in the world. Two families of snakes follow (Elapidae, including here the coral snakes and the sea snakes) and Viperidae (here represented by pitvipers) in 190 species accounts. Omitted are the few poisonous rear-fanged Colubridae. Volume 1 contains all species except the rattlesnakes, while Volume 2 covers the latter.

The species accounts lead with scientific name and original describer and date, reference to figure (drawing), map (with dots of collections and shading for the suggested range), and plates (colour photographs), synonymy, local names, English name, and etymology. For some species a quotation from an historical observation is added. Sections follow on distribution, habitat, description, similar species, and remarks (including described subspecies and relationships with other species).

As comprehensive as these accounts are, there are other topics covered. In volume 1, there is an Introduction, Regional Accounts and separate Keys to Canada and United States, Mexico and Central America, The Caribbean Islands, and South America. Volume 2 includes chapters on Venomous Snake Mimicry, The Evolution of New World Venomous Snakes, Venom Poisoning by North American Reptiles, and Snakebites in Central and South America: Epidemiology, Clinical Features Management. The volume has an 11-page Glossary, and a 116-page Literature Cited. A 28-page index is repeated to conclude each volume.

Canada has only three Crotalus: The Timber Rattlesnake $C$. horridus (Ontario, now extirpated), Prairie

\section{Whales and Dolphins of the World}

By M. Simmonds. 2004. The MIT Press, Five Cambridge Centre, Cambridge Masachusetts 02142. 160 pages, U.S. \$29.95 Cloth.

Coffee table books of cetaceans seem to be popular with authors, photographers and the buying public. Here is another fine example. I note my local library has three shelves of mammal books. Almost 20\% are on whales and the other books cover the rest of the world's 5000 or so species of mammal, a testament to the popularity of cetaceans.

While this book does not cover all the world's species it does have photographs of over 50 per cent. As you would expect the photographs are remarkably good. All the common species (common that is in books) like Blue, Sperm Humpback, Minke are there. But so too are some of the less well known and photographed, such as the Boto and Pink River Dolphin. These latter animals are not so difficult to see but are stunningly hard to capture on film.

The first half of the book is devoted to basic information on whales, similar to that found in most volumes of this type. The second half has information on the threats faced by these animals and the conservation
Rattlesnake C. viridis (Saskatchewan and Alberta), Pacific Rattlesnake C. oreganus (British Columbia) and one Sistrurus, the Massasauga S. catenatus (Ontario). Despite the through coverage elsewhere, the peripheral nature of their distributions here may account for the scant coverage of Canadian references the southernbased authors have included. Some relatively recent contributions by Pat Weatherhead formerly at Carleton University, Tony Russell at University of Calgary, and Pat Gregory at the University of Victoria and their many students are included. However, some citations for Canadian distributions are merely popularized accounts by non-Canadians such Curran's 1935 rattlesnake article in the American Museum's Natural History or Kozloff's 1976 book an animals of the Pacific northwest. Many are dated, the citation to the pioneering Canadian checklist by Logier and Toner is to the first (1955) edition rather than 1961 revision. Two references to Barbara Froom are to 1964 and 1967 articles or pamphlets whereas her 1972 book is omitted. The detailed distributional documentation in the Ontario Herpetofaunal Summary and the status reports of Committee on the Status of Endangered Species of Wildlife in Canada (COSEWIC), or the symposiums on the Massasauga and conservation promotional newsletter Rattlesnake Tales sponsored by the Metro Toronto Zoo are ignored, perhaps because they are not readily accessible in the mainstream literature.

FRANCIS R. COOK

Researcher Emeritus, Canadian Museum of Nature, Ottawa, Ontario K1P 6P4 Canada

measures in place or necessary. I also has a very odd error. The author writes of the Basques from northern France. Any Basque will tell they always lived in the Pyrenees Mountains of northern Spain and southern France.

The author list 83 species of whales and dolphins; one short of the most current list. The missing species is North Pacific Right Whale (Eubalaena japonica), recently separated by Rosenbaum et al, based on DNA. [This counting does not include Delphinus tropicalis as this is likely a variant of $D$. capensis and not a separate $84^{\text {th }}$ species]

Why should I buy this book? I can think of three reasons. Any good whale book is worth having, especially when it such fine photos. The latter half of the book contains new and up-to-date information of importance. The royalties from sales are going to the Whale and Dolphin Conservation Society, where the author is Director of Science at the aforementioned society.

ROY JOHN

2193 Emard Crescent, Beacon Hill North, Ottawa, Ontario K1J 6K5 Canada 